\title{
Microclimate Variation among Urban Land Covers: The Importance of Vertical and Horizontal Structure in Air and Land Surface Temperature Relationships ${ }^{\mathscr{O}}$
}

\author{
Steven M. Crum And G. DARrel Jenerette \\ Department of Botany and Plant Sciences, University of California, Riverside, Riverside, California
}

(Manuscript received 3 March 2017, in final form 5 July 2017)

\begin{abstract}
Air and land surface warming effects from urbanization are of increasing concern because of expanding heat-related impacts on human health. Many studies have investigated land-cover effects on air temperature $T_{a}$ or land surface temperature (LST) individually, but relatively few studies have examined the relationships between these two heat indicators and other meteorological variables. The authors investigate how land cover influences local distributions of LST, $T_{a}$, and relative humidity (RH) and their interactions. During July 2016, $30 T_{a}$ and RH sensors were deployed at two heights above the ground $(0.1$ and $1.5 \mathrm{~m})$ along with a thermal camera and an anemometer to quantify the influence of surface dynamics on atmospheric micrometeorological conditions. Sensors were distributed in Riverside, California, over five common urban land covers: asphalt, bare surface, turf grass, short trees, and tall trees. Stronger $T_{a}-\mathrm{LST}$ relationships were observed at $0.1 \mathrm{~m}$ for asphalt, bare surface, and grass and at $1.5 \mathrm{~m}$ for short and tall trees. Excluding grass, greater $T_{a}-\mathrm{LST}$ differences were found for daytime than for nighttime. To add to the complexity of $T_{a}$-LST relationships, increasing spatial variation in LST during the day for short- and tall-tree land covers were found. Furthermore, both wind velocity and LST were correlated with $T_{a}$ vertical distributions. Higher RH and lower LST, $T_{a}$, and vapor pressure deficit were found in vegetated covers. Through the use of thermal imagery and meteorological measures, it was found that distinct land-cover influences on microclimate exist and that estimates of urban $T_{a}$ using LST may improve with the use of land-cover-specific relationships.
\end{abstract}

\section{Introduction}

Urban microclimates are highly variable and respond in uncertain ways to characteristics of local land-cover composition. Land cover may influence spatial distributions of land surface temperature (LST), air temperature $T_{a}$, and relative humidity $(\mathrm{RH})$. Each of these microclimate components can have an impact on human health and energy demand (Taha 1997; Harlan et al. 2006; Parris and Hazell 2005; Barreca and Schimshack 2012). At scales relevant to human experience, vegetated and built land covers create heterogeneous patterns in air and land surface temperature that lead to cool refugia and warming hot spots within cities (Jenerette et al. 2016; Imhoff et al. 2010; Coseo and

Supplemental information related to this paper is available at the Journals Online website: https://doi.org/10.1175/JAMC-D-170054.s1.

Corresponding author: Steven Crum, scrum001@ucr.edu
Larsen 2014; Davis et al. 2016; Shiflett et al. 2017). Characterizing how vegetated and built land covers influence each of these microclimate components and their interrelationships remains an important research challenge.

The $T_{a}$ and LST are two distinct and complementary metrics of urban temperatures. Intraurban variation in $T_{a}$, associated with urban warming and cooling effects, is often greatest at night as surfaces reemit heat at different rates and wind velocity is low (Oswald et al. 2012; Shiflett et al. 2017). LST variation, however, is greatest during the day because of dynamic inputs in solar radiation (Buyantuyev and $\mathrm{Wu}$ 2010; Myint et al. 2013; Jenerette et al. 2016). Furthermore, maximum intraurban variation in $T_{a}$ is considerably less (e.g., $8^{\circ} \mathrm{C}$; Stabler et al. 2005) than that in LST (e.g., $25^{\circ} \mathrm{C}$; Jenerette et al.2011). Thus, the difference in both timing and magnitude of variation contributes to a disconnect between $T_{a}$ and LST. Whereas land surfaces affect LST at microscales of less than $10 \mathrm{~m}$ (Jenerette et al. 2016), land-cover effects on $T_{a}$ are frequently observed at 
larger scales of 20-500 m (Shashua-Bar and Hoffman 2000; Feyisa et al. 2014; Davis et al. 2016; Shiflett et al. 2017). These scaling differences are in part associated with a lack of straightforward relationships between $T_{a}$ and LST, reflecting the complexities in the local atmospheric interactions with the vertical and horizontal structure of urban land covers (Hartz et al. 2006).

If relationships between $T_{a}$ and LST can be identified, however, then thermal imagery could be used to model $T_{a}$ - the standard metric of both regional and global climate warming. LST is typically measured from a relatively coarse spatial resolution, at scales of $90 \mathrm{~m}$ or larger (e.g., Roth et al. 1989; Imhoff et al. 2010; Zhao et al. 2014), at a single time of day, and at varying heights both within and among pixels spanning tree canopies or rooftops to the ground. In contrast, most $T_{a}$ measurements are recorded continuously at one height above the ground and over standardized land-cover typesnegating vertical and land-cover effects in $T_{a}$. Whereas finescale spatiotemporal variation in LST has begun to be studied in natural and built environments (Hartz et al. 2006; Tonolla et al. 2010; Gillner et al. 2015), little is known about land-cover effects on finescale spatiotemporal variation of LST. Because of these potential sources of uncertainty, the $T_{a}$-LST linkage is rarely made and remains an important research challenge (Hartz et al. 2006; Schwarz et al. 2012). In support of this direction, some studies have identified significant correlations between $T_{a}$ and LST (e.g., Unger et al. 2009; Klok et al. 2012). When identified, the linkage between these two temperature metrics may vary throughout the day, with stronger relationships often observed at night (Kawashima et al. 2000; Schwarz et al. 2012; Shiflett et al.2017). Stronger nighttime relationships between $T_{a}$ and LST may potentially be due to lower wind velocities and reduced active heating of surfaces at night (Shiflett et al. 2017). The $T_{a}$ is strongly influenced by horizontal convection (Landsberg 1981; Santamouris 2015). Thus, using LST to represent local atmospheric conditions can lead to uncertainties in cooling effectiveness of different urban management strategies.

In moderating urban heat, vegetation is frequently highlighted as a valuable urban management strategy. The effects of vegetation on microclimate are not well characterized at finescales, however, especially those relevant to the human experience. Vegetation can decrease $T_{a}$ and LST by increasing latent heat flux via evapotranspiration, increasing surface albedo relative to built surfaces, and decreasing sensible heat flux via shading (Doran et al. 1998; Yang et al. 2011; Jenerette et al. 2011; Chakraborty et al. 2015). Alternatively, tree canopies may increase nighttime temperatures by providing insulation from high wind velocities, which reduces the dissipation of surface radiation to the surrounding environment (Gillner et al. 2015). These microclimate effects may vary with the extent of canopy cover and vegetation type. Individual large tree canopies can reduce $T_{a}$ by $1^{\circ}-2.5^{\circ} \mathrm{C}$ (Streiling and Matzarakis 2003; Lin and Lin 2010; Lee et al. 2013), whereas small, isolated tree canopies may have no effect on $T_{a}$ (Armson et al. 2013). Likewise, turf-grass land cover may reduce LST (Jenerette et al. 2016) in urban areas.

In addition to influencing LST and $T_{a}$, vegetated land covers in arid and semiarid environments are also associated with higher rates of evapotranspiration and lower wind velocity, which may lead to higher RH (Souch and Souch 1993; Potchter et al. 2006; Gillner et al. 2015). Higher humidity associated with vegetation may counter the direct cooling benefits through greater human-perceived temperatures (Steadman 1979; Hall et al. 2016), heat-related mortality (Barreca and Schimshack 2012), and incidents of respiratorysystem diseases (Gao et al. 2014). Increasing RH will also lower the vapor pressure deficit (VPD) —an important variable determining aridity and tree physiological performance (Chen et al. 2012). The changes in RH and VPD associated with vegetation may vary with height above the ground because of moisture inputs from crown-level transpiration and groundlevel irrigation.

To address the uncertainties in the relationships among measures of microclimate and the influence of built and vegetated land covers on these relationships, we ask: How does land cover influence microscale distributions of LST, $T_{a}$, and RH and their interactions? To address this question, we analyzed patterns of $T_{a}$ and RH lapse rates using sensors at two heights ( 0.1 and $1.5 \mathrm{~m}$ ) at five common urban land cover types-asphalt, bare surface, turf grass, small tree, and tall tree-in Riverside, California. To investigate air and surface temperature linkages, we measured LST at each land cover using tower-mounted high-resolution thermal imagery over a $24-\mathrm{h}$ period. We further explored the potential role of wind velocity on $T_{a}$ and $\mathrm{RH}$ lapse rates. At vegetated land covers, we anticipated lower $T_{a}$ and higher RH at the height of transpiring vegetation. Furthermore, we anticipated higher $T_{a}$ and lower $\mathrm{RH}$ at $0.1 \mathrm{~m}$ at asphalt and bare surfaces because of increased surface temperatures and heat fluxes. Reflecting the vertical height of sun-exposed surfaces, stronger $T_{a}$-LST relationships were anticipated at $0.1 \mathrm{~m}$ at asphalt, bare-surface, and grass land covers and $1.5 \mathrm{~m}$ at short- and tall-canopy land covers. The $T_{a}$-LST differences and $T_{a}$ lapse rates were anticipated to be larger during the day because of increased evaporative cooling effects and surface heat fluxes. We also anticipated that 
intra-land-cover variation in LST would increase in the morning hours because of differential heating of surfaces. Understanding these land-cover drivers of microclimate is a necessary step in predicting and mitigating urban warming effects (Oswald et al. 2012; Coseo and Larsen 2014; Gillner et al. 2015; Davis et al. 2016).

\section{Methods}

\section{a. Study site}

Our study site is located at the Agricultural Experiment Station $\left(33.965^{\circ}\right.$ latitude, $-117.338^{\circ}$ longitude) at the University of California, Riverside. Riverside is a part of the Los Angeles, California, metropolitan region of 18 million residents. The region is characterized by a Mediterranean climate with hot, dry summers and cool, wet winters and spans a gradient from semiarid coastal climate to arid desert climate. Riverside is situated at an intermediate position of this climate gradient, with mean annual precipitation of $262 \mathrm{~mm}$ and mean annual temperature of $19.6^{\circ} \mathrm{C}$. Average maximum summer temperatures are $35.0^{\circ} \mathrm{C}$ in July. At neighborhood scales, vegetation in this region can have a prominent effect on both $T_{a}$ and LST (Tayyebi and Jenerette 2016; Shiflett et al.2017). Characteristic of summer in this region, there was no precipitation during the sampling period.

Five plots located within $650 \mathrm{~m}$ of each other, representing common land covers-asphalt parking lot, bare soil surface, turf grass (Festuca arundinacea and Poa pratensis mixture), short Valencia orange orchard (Citrus $\times$ sinensis), and tall Valencia orange orchardwere selected (Fig. 1a of the online supplemental material). The bare-surface cover was unvegetated loam soil with low gravimetric water content $(0.22 \% \pm 0.1 \%$ at $5 \mathrm{~cm} ; n=3)$. Both tree height and canopy cover were greater at the tall orchard ( $4 \mathrm{~m}$ and $62.5 \%$, respectively) than at the short orchard ( $3 \mathrm{~m}$ and $50 \%$, respectively). Interspace widths were the same for both short and tall orchards $(3 \mathrm{~m})$, with different tree widths $(3$ and $5 \mathrm{~m}$, respectively). Interspace soil gravimetric water content was similar for both short and tall orchard covers $(3.4 \% \pm$ $2.5 \%$ and $2.8 \% \pm 2.9 \%$ at $5 \mathrm{~cm}$, respectively; $n=3)$. The land-cover plots were similar in size, ranging approximately from 6000 to $8500 \mathrm{~m}^{2}$. All temperature and humidity measurements were collected in a 17-day time period from 15 to 31 July 2016 [corresponding to yearday (DOY) 197 and 213], during the warmest period of the year. Sunrise, solar noon, and sunset midway through the study (DOY 204) were at 0555 , 1256, and 1957 Pacific daylight time (PDT: UTC $7 \mathrm{~h}$ ), respectively. Simultaneous with temperature and humidity measurements, infrared imagery and wind velocity were recorded for a 24-h period at each land cover.

\section{b. Data acquisition}

To test the effect of land cover on $T_{a}$ at each of the five plots, three replicate temperature sensors separated by approximately $4 \mathrm{~m}$ (Maxim Integrated Products, Inc., iButton Thermocron DS1922L) with an accuracy of $\pm 0.5^{\circ} \mathrm{C}$ from $10^{\circ}$ to $65^{\circ} \mathrm{C}$. These sensors were mounted at two heights $(0.1$ and $1.5 \mathrm{~m})$ from the ground on white polyvinyl chloride (PVC) pipes (online supplemental Fig. 1c) near the center of each plot (5 land covers $\times 2$ heights $\times 3$ replicates $=30$ total sensors). To explore $\mathrm{RH}$ effects in each plot, one temperature and humidity sensor (Maxim Integrated Products iButton Hydrocron DS1923) with a temperature accuracy of $\pm 0.5^{\circ} \mathrm{C}$ from $-10^{\circ}$ to $65^{\circ} \mathrm{C}$ and $\mathrm{RH}$ accuracy of $\pm 0.5 \%$ from $0 \%$ to $100 \%$ was mounted at each of two heights $(0.1$ and $1.5 \mathrm{~m}$ ) from the ground (5 land covers $\times 2$ heights $\times 1$ replicate $=10$ total sensors). These sensors are small, self-contained units with onboard memory and measuring $15 \mathrm{~mm}$ in diameter and $5 \mathrm{~mm}$ high. Readings were collected every hour throughout the study period. To shield each sensor from direct solar radiation, they were housed in custom rigid polystyrene cylindrical white cups measuring $47 \mathrm{~mm}$ in diameter and $30 \mathrm{~mm}$ high. The bottoms of the shields were exposed to air, allowing adequate ventilation, with an additional radiation shield hanging $20 \mathrm{~mm}$ below the sensor to preclude direct surface longwave radiation. Supporting the effectiveness of the custom shielding system, a prior study found that temperature differences between iButton and research-grade temperature sensors were not observed in the field (Crum et al. 2017).

Alongside $T_{a}$ and RH observations, tower-mounted LST thermal imagery in the $7.5-13-\mu \mathrm{m}$ spectral range (FLIR Systems, Inc., SC660) with an accuracy of $\pm 1.0^{\circ} \mathrm{C}$ from $-40^{\circ}$ to $1500^{\circ} \mathrm{C}$ was recorded every $15 \mathrm{~min}$ for a 24-h period at each land cover. The 24 -h sequences were recorded in succession at asphalt, tall-tree, short-tree, bare-surface, and turf-grass land covers from 15 to 31 July 2016 on cloud-free days with average maximum solar irradiance of $861.00 \pm 6.26 \mathrm{~W} \mathrm{~m}^{-2}$ (http://www. cimis.water.ca.gov/WSNReportCriteria.aspx; accessed 7 December 2016). Although some microclimate studies choose dates with weak winds to negate the effects of horizontal advection, we did not explicitly exclude these days since we were investigating the effects of wind on $T_{a}$. The thermal camera was mounted on a mobile tower $6 \mathrm{~m}$ above each surface at a $55^{\circ}$ angle, capturing approximately $20 \mathrm{~m} \times 15 \mathrm{~m}$ of surface area (online supplemental Fig. 1b). This was the highest allowable 


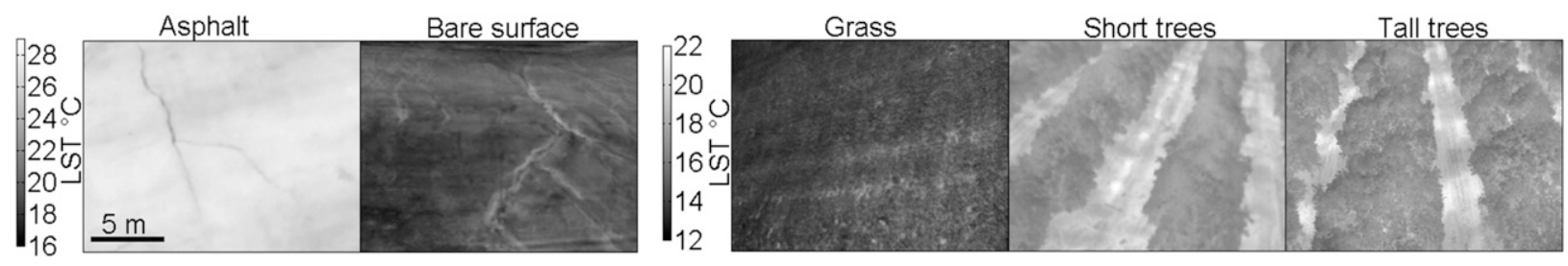

FIG. 1. Representative infrared images from asphalt, bare-surface, grass, short-tree, and tall-tree land covers at midnight used to assess LST relationships.

angle at this height since steeper angles capture the platform of the mobile tower. Each $640 \times 480$ pixel thermal image was corrected for surface emissivity, distance of camera to surface, atmospheric temperature and humidity, and estimated camera temperature (Fig. 1). Surface emissivity was estimated using values from prior studies (Lo and Quattrochi 2003; Chen 2015; Gao et al. 2015). We used emissivity values of 0.95 for asphalt and for short and tall trees, 0.93 for bare surface, and 0.97 for grass. Continuous thermal imaging of urban (e.g., Gillner et al. 2015) and natural (e.g., Tonolla et al. 2010) surfaces is a recent development. The methods we used to measure LST have been demonstrated to correlate well with generally reliable thermocouplemeasured surface temperature (Aubrecht et al. 2016). Furthermore, the effects of wind velocity on microclimate lapse rate were measured using an anemometer (R. M. Young Company Model 03002 anemometer) with an accuracy of $\pm 0.5 \mathrm{~m} \mathrm{~s}^{-1}$ from 0 to $50 \mathrm{~m} \mathrm{~s}^{-1}$. Data were recorded every $15 \mathrm{~min}$ for a 24 -h period at each land cover. The anemometer was mounted on a leveled tripod $2 \mathrm{~m}$ above the ground.

\section{c. Analysis}

The $T_{a}, \mathrm{RH}, \mathrm{VPD}$, and LST land-cover effects were quantified using several measures. Lapse rates in $T_{a}$, $\mathrm{RH}$, and VPD were quantified at each land cover using the average difference between all replicate high $(1.5 \mathrm{~m})$ and low $(0.1 \mathrm{~m})$ sensors over the change in vertical height:

Lapse rate $=($ value at $1.5 \mathrm{~m}-$ value at $0.1 \mathrm{~m}) /(\Delta$ Height $)$.

Daily variation in land-cover effects on lapse rates and the slope of the linear regression between $T_{a}$ and $\mathrm{RH}$ were calculated using hourly averages from the entire study period. Steep hourly slopes from $T_{a}$ and RH relationships indicate that warmer periods have a larger effect on RH. To quantify wind and LST effects on lapse rates of $T_{a}$ and $\mathrm{RH}$, linear regressions between $T_{a}$ lapse rate and wind velocity, between $T_{a}$ lapse rate and LST, and between $\mathrm{RH}$ lapse rate and wind velocity were analyzed. To quantify air and surface temperature relationships, linear regressions between mean $T_{a}$ at two heights and mean LST over the entire $640 \times 480$ pixel thermal images were calculated. Furthermore, differences $\Delta T$ between $T_{a}$ and LST were calculated using averages among $T_{a}$ replicates and one LST image every hour over the sampled 24-h period. The coefficient of variation $(\mathrm{CV})$ was used to quantify spatial variations in LST. The CV is a dimensionless quantity of variation normalized by the sample mean, commonly expressed as a whole number percent, and is frequently used to assess spatiotemporal landscape variation (Crum et al. 2016). Unstandardized measures of variation (e.g., standard deviation) would not be suitable for this study because values change with the sample mean, obscuring relative changes in variation.

\section{Results}

There were differing land-cover effects on microclimate, with greater cooling, RH, and lower VPD at vegetated land covers than at unvegetated land covers (Table 1 in the online supplemental material). The cooling effect was largest between asphalt and grass land covers at $0.1 \mathrm{~m}$, with a mean $T_{a}$ reduction of $5.54^{\circ} \pm 2.97^{\circ} \mathrm{C}$. The largest mean $T_{a}$ difference at $1.5 \mathrm{~m}$ was between asphalt and short-tree land covers, with a mean $T_{a}$ reduction of $2.17^{\circ} \pm 1.59^{\circ} \mathrm{C}$. $\mathrm{RH}$ varied among land covers, with the largest effect between grass and asphalt land covers, with a mean reduction of $31.98 \% \pm 10.64 \%$ and $6.40 \% \pm$ $4.53 \%$ at 0.1 and $1.5 \mathrm{~m}$, respectively. Likewise, the largest land-cover effect on mean VPD was between grass and asphalt, with a mean increase of $1.21 \pm 0.55$ and $0.23 \pm$ $0.14 \mathrm{kPa}$ at 0.1 and $1.5 \mathrm{~m}$, respectively. Correlations between $T_{a}$ and $\mathrm{RH}$ at both heights over all land-cover types were stronger during the night than during the day, with weaker relationships at $0.1 \mathrm{~m}$ (supplemental Fig. 2). There were no distinguishable changes in this relationship among land covers.

\section{a. Microclimate lapse rates}

The $T_{a}$ lapse rate, measured as the difference between $T_{a}$ at 1.5 and $0.1 \mathrm{~m}$ over the change in vertical height, had 


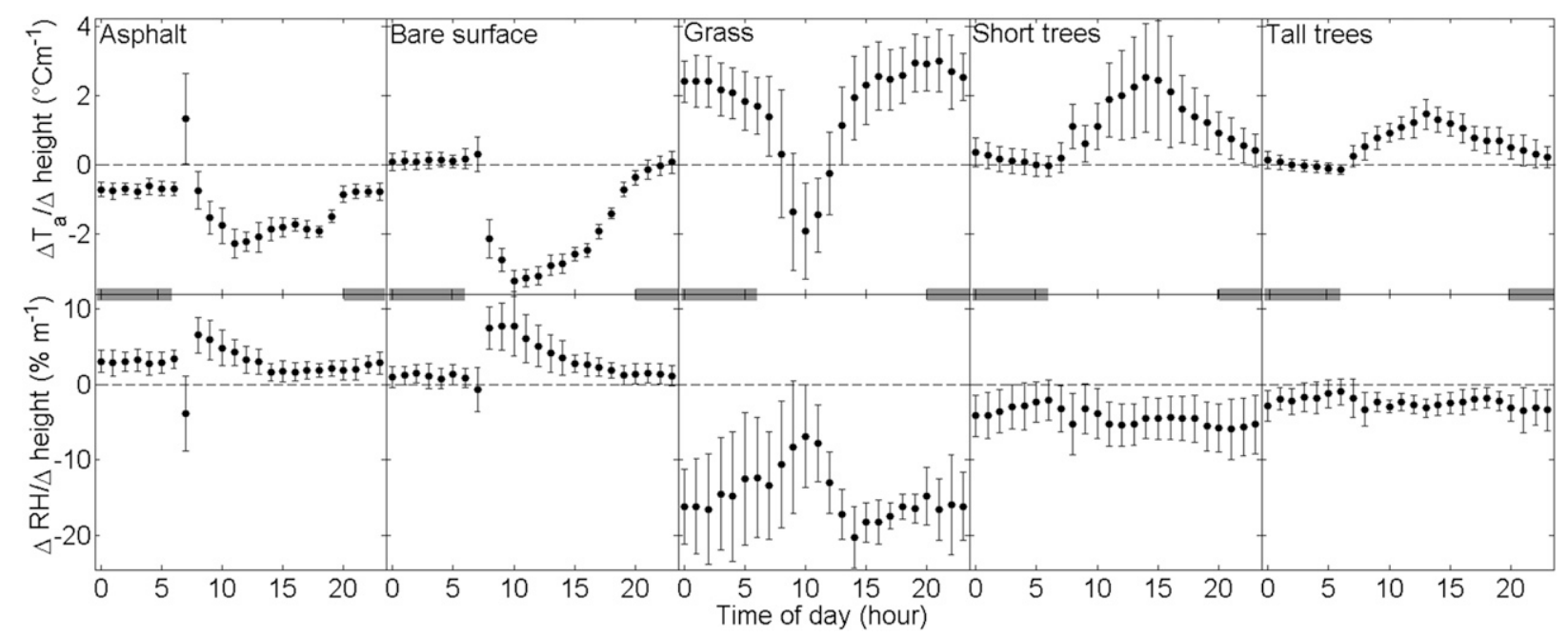

FIG. 2. Divergent daily changes in $T_{a}$ lapse rate $\left[\Delta T_{a} / \Delta\right.$ (sensor height), $\left.\pm \mathrm{SD}\right]$ over five land-cover types varied from decreasing daytime lapse rates to increasing daytime lapse rates. The $\mathrm{RH}$ lapse rate $[\Delta \mathrm{RH} / \Delta$ (sensor height), $\pm \mathrm{SD}]$ over five land-cover types varied from positive lapse rates (asphalt and bare surface) to negative lapse rates (grass and short and tall trees) with little daily trend. The $T_{a}$ lapse rates were calculated as the mean three replicates at each land cover. Hourly mean values were calculated using data collected in a 17-day time period from 15 to $31 \mathrm{Jul} 2016$. Gray bars indicate approximate nighttime hours after sunset and before sunrise.

strong daily patterns among land-cover types (Fig. 2). These strong daily patterns in $T_{a}$ lapse rate indicate temporal changes of surface heat fluxes and horizontal convection. Lapse rates were generally negative for asphalt and bare-surface land covers during the day (minimum lapse rate $=-2.29^{\circ} \pm 0.41^{\circ}$ and $-3.38^{\circ} \pm$ $0.30^{\circ} \mathrm{C} \mathrm{m}^{-1}$ at 1100 and $1000 \mathrm{PDT}$, respectively), with values approaching zero at night. In contrast, lapse rates were generally positive for short- and tall-tree land covers during the day (maximum lapse rate $=2.52^{\circ} \pm$ $1.57^{\circ}$ and $1.47^{\circ} \pm 0.42^{\circ} \mathrm{Cm}^{-1}$ at 1400 and $1300 \mathrm{PDT}$, respectively), with values approaching zero at night. The grass land cover had a different pattern, with positive lapse rates at night (maximum lapse rate $=3.02^{\circ} \pm$ $0.91^{\circ} \mathrm{C} \mathrm{m}^{-1}$ at $2100 \mathrm{PDT}$ ) and rapidly decreasing lapse rates during the day (minimum lapse rate $=-1.92^{\circ} \pm$ $1.40^{\circ} \mathrm{Cm}^{-1}$ at $\left.1000 \mathrm{PDT}\right)$. Approximately $1 \mathrm{~h}$ after sunrise (0700 PDT) at the asphalt land cover there was an outlier in lapse rate. This outlier was more than 3 standard deviations (SD) from the daily mean $\left(-1.18^{\circ} \pm\right.$ $\left.0.80^{\circ} \mathrm{Cm}^{-1}\right)$ and 0600 and 0800 PDT values $\left(-0.70^{\circ} \pm\right.$ $0.20^{\circ}$ and $-0.75^{\circ} \pm 0.54^{\circ} \mathrm{Cm}^{-1}$, respectively). After reinspection of the site, it was determined that solar reflection from nearby surfaces likely caused this unexpected value.

RH lapse rate had less noticeable daily patterns among land-cover types than did $T_{a}$ lapse rates (Fig. 2). RH lapse rates varied from positive (asphalt and bare surface) to negative (grass and short and tall trees). There was a steep increase in lapse rates at 0800 PDT for both asphalt and bare-surface land covers (maximum lapse rate $=6.57 \% \pm 2.37 \%$ and $7.74 \% \pm 3.92 \% \mathrm{~m}^{-1}$ at 0800 and 1000 PDT, respectively), whereas grass had a steady decline starting at 1100 PDT (minimum lapse rate $=-20.24 \% \pm 4.04 \% \mathrm{~m}^{-1}$ at $\left.1400 \mathrm{PDT}\right)$. There were considerable differences in the range of lapse rates among land-cover types: from $2.47 \% \mathrm{~m}^{-1}$ at the tall-tree land cover to $13.38 \% \mathrm{~m}^{-1}$ at the grass land cover.

VPD, which is derived from both $T_{a}$ and RH data, had strong daily changes in lapse rate among land-cover types that, excluding the grass land cover, reflected patterns in $T_{a}$ lapse rate (supplemental Fig. 3). VPD lapse rates were generally negative for asphalt and baresurface land covers during the day (minimum lapse rate $=-0.95 \pm 0.17$ and $-1.40 \pm 0.15 \mathrm{kPa} \mathrm{m}^{-1}$ at 1100 and 1200 PDT, respectively), with values approaching zero at night. In contrast, lapse rates were generally positive for short- and tall-tree land covers during the day (maximum lapse rate $=1.02 \pm 0.73$ and $0.65 \pm$ $0.37 \mathrm{kPa} \mathrm{m}^{-1}$ at 1500 and 1400 PDT, respectively) with values approaching zero at night. The grass land cover had a different pattern, with positive and increasing lapse rates during the day (maximum lapse rate $=1.70 \pm$ $0.67 \mathrm{kPa} \mathrm{m}^{-1}$ at 1400 PDT).

For asphalt and bare-surface land covers, we observed a negative relationship between $T_{a}$ lapse rate and wind velocity, with a stronger correlation at the asphalt land cover (Fig. 3). The counterclockwise hysteresis-like effect at the bare-surface plot may explain its weaker correlation. For short- and tall-tree land covers, we observed a positive relationship between $T_{a}$ lapse rate and wind velocity, with a stronger correlation 


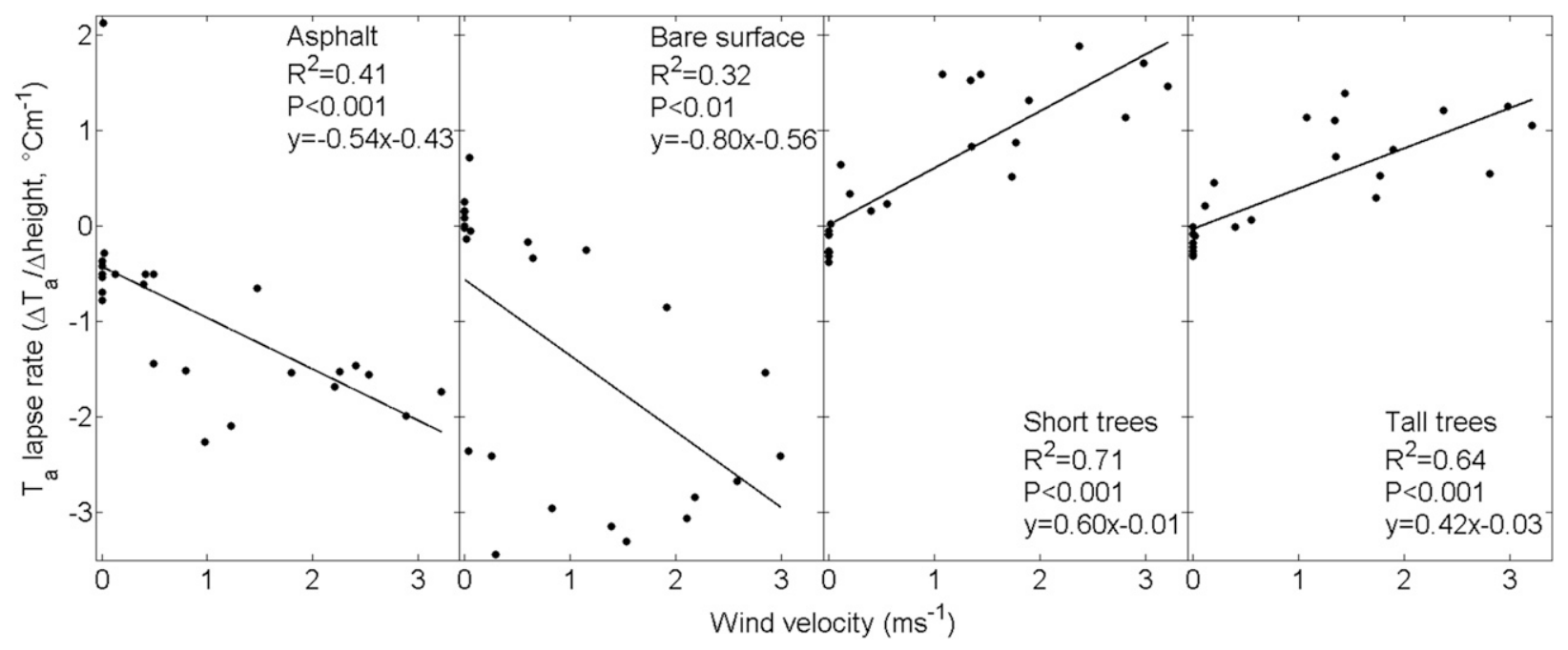

FIG. 3. The $T_{a}$ lapse rate $\left[\Delta T_{a} / \Delta\right.$ (sensor height)] is negatively correlated with wind velocity for asphalt (correlation coefficient squared $R^{2}=0.41$; significance level $\left.P<0.001\right)$ and bare-surface $\left(R^{2}=0.32 ; P<0.01\right)$ land-cover types and is positively correlated with wind velocity in short-tree $\left(R^{2}=0.71 ; P<0.001\right)$ and tall-tree $\left(R^{2}=0.64 ; P<0.001\right)$ land covers. There was not a significant relationship $(P>0.05)$ for grass cover. Wind velocity was measured for a 24 -h period at each land cover $(n=24)$. The $T_{a}$ lapse rates were calculated as the mean three replicates at each land cover.

at the short-tree land cover. Conversely, we observed a negative relationship between RH lapse rate and wind velocity, with a stronger correlation at the short-tree land cover (Fig. 4).

\section{b. Land surface temperature variability}

Land-cover effects on LST differed in magnitude, variation, and timing (Fig. 5a). The time of maximum LST varied between 1200 and 1400 PDT. Consistent with prior research, the mean maximum LST was at 1300 PDT, near solar noon (1255 PDT; Grimmond and Oke 1995). The highest range in LST among land covers was $29.98^{\circ} \mathrm{C}$ during the day at $1400 \mathrm{PDT}$, and the lowest range was $7.77^{\circ} \mathrm{C}$ before sunrise at 0500 PDT. Asphalt was consistently the warmest surface throughout the day, whereas grass and short- and tall-tree land covers were the coolest at different times.

Spatial CV of LST varied throughout the day among land covers (Fig. 5b). There was increasing variation in both short- and tall-tree land covers during the day, with maximum values of 24.4 and 20.98 at 1330 and 1300 PDT, respectively. These increasing trends began shortly after sunrise around 0630 PDT and returned to nighttime levels shortly after sunset around 2100 PDT. Asphalt, bare-surface, and grass land covers have lessnoticeable patterns in variation of LST. Variation in the asphalt land cover was consistent throughout the day except for a dip in variation shortly after sunrise and a spike in variation at 0830 PDT. Variation of LST in the grass land cover was highest at night before decreasing around sunrise, with a steady increase in variation that topped out at 1300 PDT. Furthermore, relative to bare and asphalt covers, vegetated covers had elevated variation at night.

\section{c. Air and land surface temperature linkage}

There were divergent $T_{a}$-LST relationships among land covers and heights (Table 1). The strongest correlation was between $T_{a}$ at $0.1 \mathrm{~m}$ and LST in the asphalt land cover, and the weakest correlation was at $1.5 \mathrm{~m}$ in the grass land cover. For asphalt, bare-surface, and grass land covers, there were higher correlations at $0.1 \mathrm{~m}$ than at $1.5 \mathrm{~m}$. Likewise, there were steeper slopes at $0.1 \mathrm{~m}$ than at $1.5 \mathrm{~m}$. Conversely, for short- and tall-tree land covers, there were higher correlations at $1.5 \mathrm{~m}$ than at $0.1 \mathrm{~m}$. Likewise, there were steeper slopes at $1.5 \mathrm{~m}$ than at $0.1 \mathrm{~m}$. Daily changes in the difference between $T_{a}$ and LST $(\Delta T)$ at 1.5 and $0.1 \mathrm{~m}$ over five land covers show divergent relationships (Fig. 6). Whereas asphalt and bare-surface land covers have the greatest $\Delta T$ at $1.5 \mathrm{~m}$ during the day $\left(-24.82^{\circ} \pm 0.34^{\circ}\right.$ and $-18.74^{\circ} \pm 0.60^{\circ} \mathrm{C}$ at 1300 and 1200 PDT, respectively), grass and short- and tall-tree land covers have the greatest $\Delta T$ at $0.1 \mathrm{~m}\left(11.19^{\circ} \pm\right.$ $0.94^{\circ},-9.6^{\circ} \pm 0.66^{\circ}$, and $-5.1^{\circ} \pm 1.44^{\circ} \mathrm{C}$ at 1800,1200 , and 1200 PDT, respectively). The $\Delta T$ was smallest for asphalt, grass, bare-surface, and short- and tall-tree land covers during the night, morning, or late-afternoon hours $\left(-4.70^{\circ} \pm 0.10^{\circ},-0.5^{\circ} \pm 0.28^{\circ}, 0.39^{\circ} \pm 0.45^{\circ}\right.$, $0.20^{\circ} \pm 0.24^{\circ}$, and $-0.06^{\circ} \pm 1.34^{\circ} \mathrm{C}$ at $0400,0400,2300$, 0700 , and 1700 PDT, respectively). Differences in $\Delta T$ 


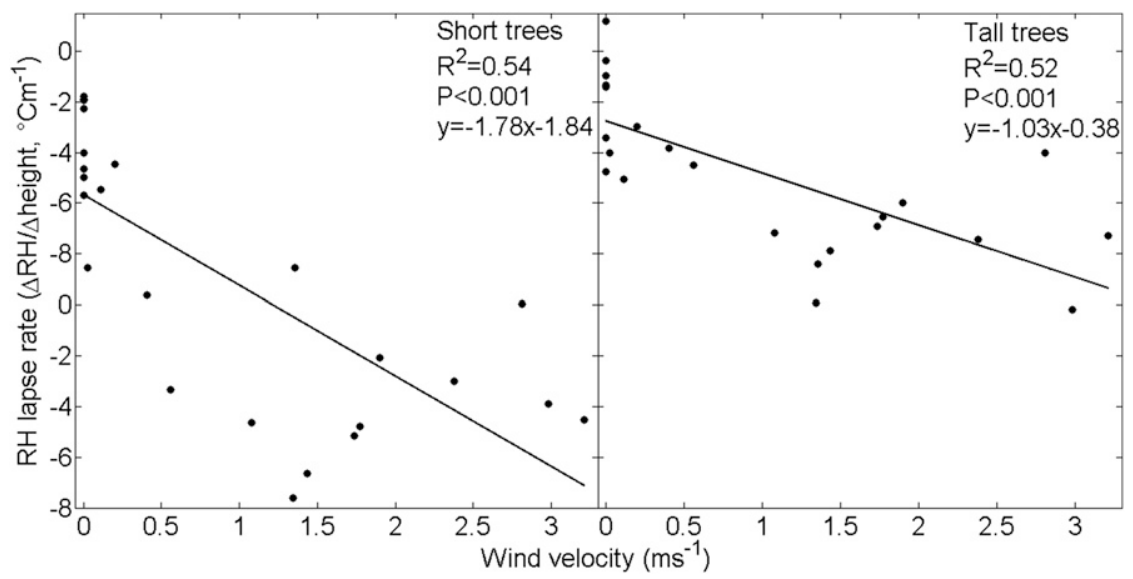

FIG. 4. The RH lapse rate $[\Delta \mathrm{RH} / \Delta$ (sensor height) $]$ is negatively correlated with wind velocity for short-tree $\left(R^{2}=0.54 ; P<0.001\right)$ and tall-tree $\left(R^{2}=0.52 ; P<0.001\right)$ land covers. There were no significant relationships $(P>0.05)$ for asphalt, bare-surface, and grass covers. Wind velocity was measured for a 24 -h period at each land cover $(n=24)$.

between 1.5 and $0.1 \mathrm{~m}$ were greatest during the day for all land covers $\left(3.64^{\circ}, 4.29^{\circ}, 5.31^{\circ}, 2.63^{\circ}\right.$, and $0.76^{\circ} \mathrm{C}$ at $1200,1300,2000,1300$, and 1400 PDT, respectively).

For asphalt, bare-surface, and grass land covers, we observed a negative relationship between $T_{a}$ lapse rate and LST, with the strongest correlation at the baresurface land cover (Fig. 7). For short- and tall-tree land covers, we observed a positive relationship between $T_{a}$ lapse rate and LST, with a stronger correlation at the short-tree land cover.

\section{Discussion}

Important for human health and tree physiology (Jenerette et al. 2011; Barreca and Schimshack 2012;
Litvak et al. 2013), we found that vegetated land covers increased canopy-level RH and decreased LST, $T_{a}$, and VPD. We further found relationships among wind velocity and micrometeorological lapse rates across contrasting land-cover types. The resulting vertical profiles in micrometeorological conditions were influenced by land-cover-specific LST relationships. The differences in surface and atmosphere temperatures among relatively homogeneous land covers likely explain the frequent uncertainties associated with LST data at coarse scales $(<90 \mathrm{~m})$ that include mixtures of land covers. Identifying how urban land covers differ in their surfaceatmosphere temperature coupling has been noted as an important research challenge for predicting and reducing urban warming effects (Hartz et al. 2006;
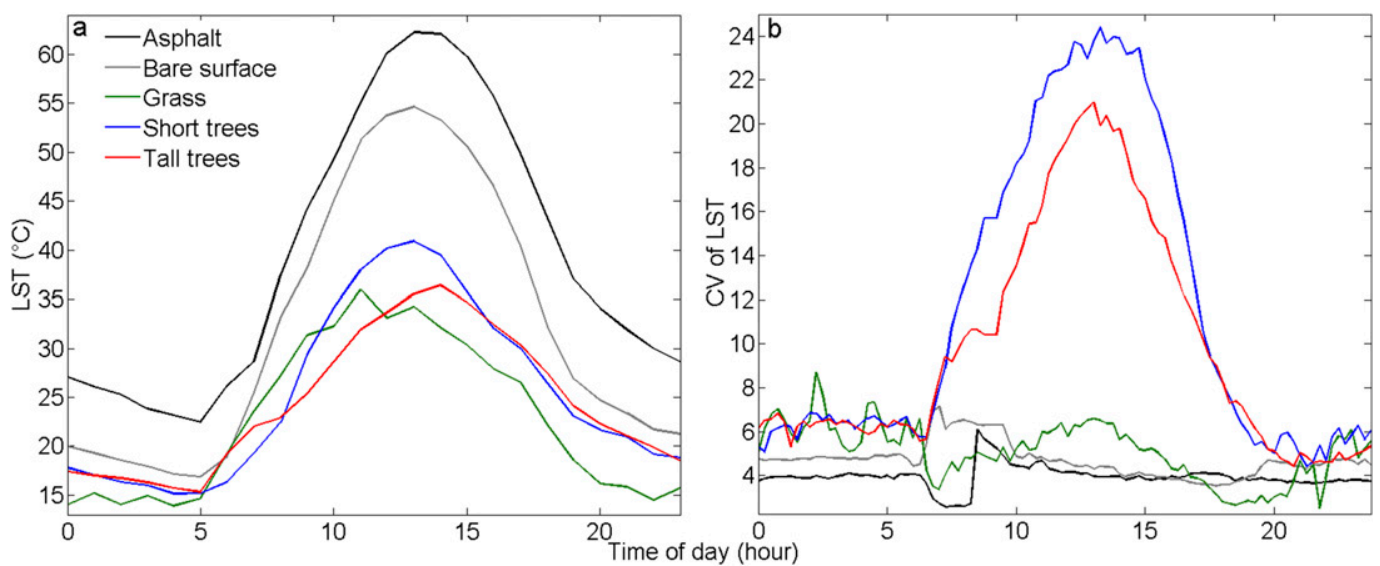

FIG. 5. (a) LST varied among land-cover types, with the highest range in temperatures during midday. (b) Spatial coefficient of variation of land surface temperature increased during the day for short- and tall-tree land covers, with relatively consistent levels for asphalt, bare-surface, and grass land-cover types. 
TABLE 1. Linear-regression statistics between $T_{a}$ at two heights above ground level and LST for five land covers; $P<0.001$ for all regressions.

\begin{tabular}{lcccc}
\hline \hline & $R^{2}$ & $F$ value & Slope & Intercept \\
\hline Asphalt & & & & \\
$0.1 \mathrm{~m}$ & 0.97 & 618.56 & 0.59 & 5.79 \\
$1.5 \mathrm{~m}$ & 0.96 & 539.08 & 0.53 & 6.11 \\
Bare surface & & & & \\
$\quad 0.1 \mathrm{~m}$ & 0.94 & 339.00 & 0.63 & 8.63 \\
$1.5 \mathrm{~m}$ & 0.92 & 267.61 & 0.49 & 11.09 \\
Grass & & & & \\
$0.1 \mathrm{~m}$ & 0.93 & 294.12 & 1.08 & 0.48 \\
$1.5 \mathrm{~m}$ & 0.84 & 118.80 & 0.88 & 7.81 \\
Short trees & & & & \\
$0.1 \mathrm{~m}$ & 0.92 & 257.54 & 0.61 & 8.36 \\
$1.5 \mathrm{~m}$ & 0.94 & 325.07 & 0.72 & 6.21 \\
Tall trees & & & & \\
$0.1 \mathrm{~m}$ & 0.92 & 244.83 & 0.74 & 5.51 \\
$1.5 \mathrm{~m}$ & 0.96 & 487.16 & 0.89 & 2.70 \\
\hline
\end{tabular}

Schwarz et al. 2012; Shiflett et al. 2017), and this is the first study to quantify relationships between vertical $T_{a}$ gradients and LST among common urban land covers. Our single-patch evaluation provides direction for subsequent study of $T_{a}$-LST relationships and other microclimate evaluations in more-complex land-cover configurations. Urban environments typically feature intricate arrangements of land covers, and therefore factors such as height-to-width ratio of the street, anthropogenic heat sources, surface albedo, tree canopy density, tree species, below-tree ground cover, and tree age and vitality will add complexity to our findings (Oke 1987; Taha 1997; Shashua-Bar and Hoffman 2000; Gillner et al. 2015). We recommend research directed to evaluating microclimate lapse rates and $T_{a}$-LST relationships in mixed urban land covers using highresolution thermal imagery paired with intensive networks of meteorological sensors.

\section{a. Relationships between vertical $T_{a}$ gradients and $T_{a}-L S T$ relationships}

We found that $T_{a}$ lapse rates were coupled to $T_{a}$-LST relationships. Variation in lapse rates among land covers account in part for poor relationships between $T_{a}$ and LST that have been found previously in the literature where standard meteorological measurements generally do not characterize land-cover effects on the vertical structure of $T_{a}$. In plots that have little threedimensional structure, LST predominantly measures the ground surface. Supporting this hypothesis, in asphalt, bare-surface, and grass plots, we found stronger $T_{a}$-LST relationships at $0.1 \mathrm{~m}$. Whereas asphalt and bare-surface land covers had higher $T_{a}$ at $0.1 \mathrm{~m}$, the grass land cover had lower temperatures at $0.1 \mathrm{~m}$, indicating near-surface evaporative cooling by grass. Conversely, in plots that had greater three-dimensional structure, LST measures varying heights above ground level from the ground surface to the top of the canopy. Consistent with greater three-dimensional structure, at short- and tall-tree plots, we found stronger $T_{a}$-LST relationships at $1.5 \mathrm{~m}$. In addition, positive $T_{a}$ lapse rates at shortand tall-tree plots indicate canopy-level warming or

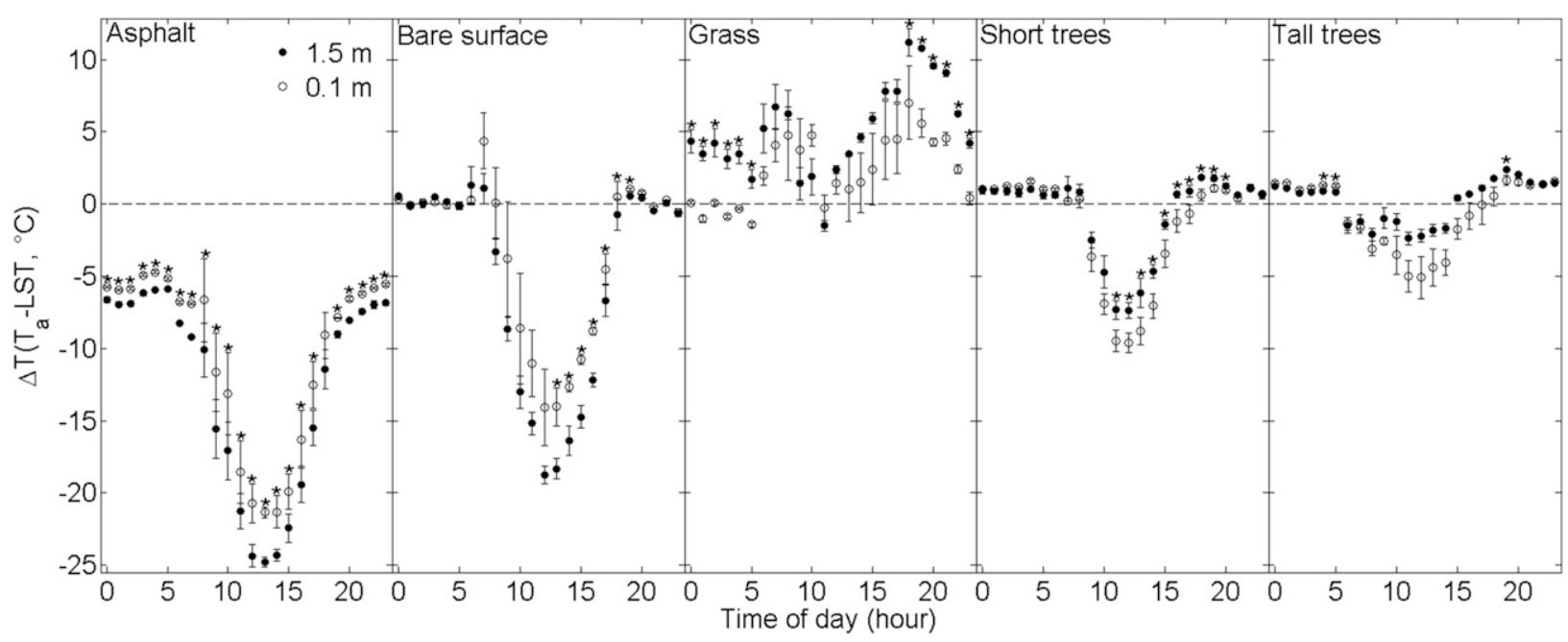

FIG. 6. Daily changes in the difference between $T_{a}$ and LST $\left(\Delta T\right.$, or $\left.T_{a}-\mathrm{LST}\right)$ at 1.5 and $0.1 \mathrm{~m}$ over five land cover types $( \pm \mathrm{SD})$ show different relationships among land-cover types. Whereas asphalt and bare surfaces have the greatest $\Delta T$ at $1.5 \mathrm{~m}$ during the day, grass and short- and talltree land covers have the greatest $\Delta T$ at $0.1 \mathrm{~m}$. Each data point corresponds to the average difference between mean $T_{a}$ and LST calculated hourly for one day. The asterisk denotes significant differences $(P<0.05)$ between 1.5 - and $0.1-\mathrm{m} \Delta T$ values using a paired Student's $t$ test. 


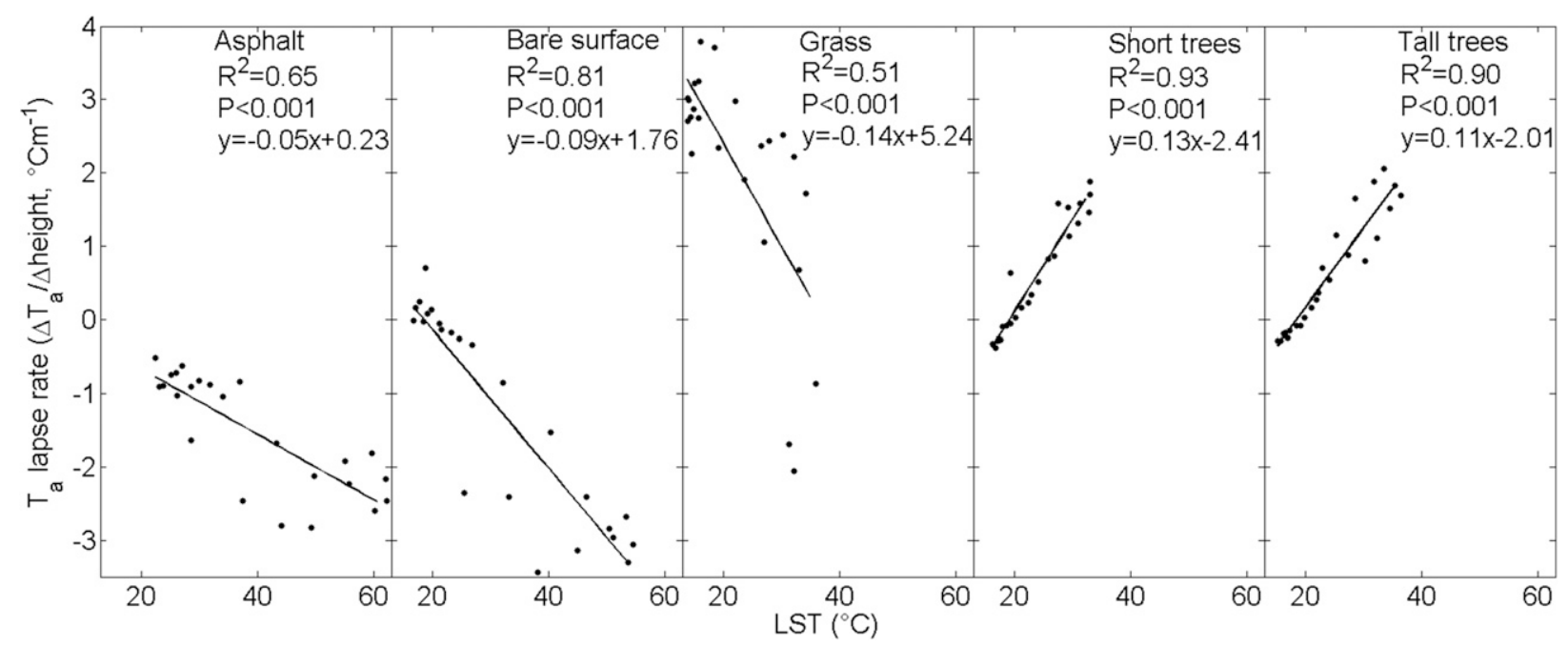

FIG. 7. The $T_{a}$ lapse rate $\left[\Delta T_{a} / \Delta\right.$ (sensor height) $]$ is negatively correlated with LST for asphalt $\left(R^{2}=0.65 ; P<0.001\right)$, bare-surface $\left(R^{2}=\right.$ $0.81 ; P<0.001)$, and grass $\left(R^{2}=0.51 ; P<0.001\right)$ land-cover types and is positively correlated with LST in short-tree $\left(R^{2}=0.93 ; P<0.001\right)$ and tall-tree $\left(R^{2}=0.90 ; P<0.001\right)$ land cover. LST was measured for a 24 -h period at each land cover $(n=24)$.

surface-shading effects. Furthermore, in an indication of canopy-size effects, we found stronger $T_{a}$-LST relationships at $1.5 \mathrm{~m}$ in the tall-tree cover. Other micrometeorological factors, including wind velocity, may add complexity to the $T_{a}$-LST relationship.

Although wind may have minimal effects on patterns of LST, $T_{a}$ is strongly influenced by horizontal convection (Landsberg 1981; Imhoff et al. 2010; Zhao et al. 2014). At whole-city scales, $T_{a}$ differences between rural and urban areas are reduced during windy days (Landsberg 1981; Gallo et al. 1993; Santamouris 2015). Microadvection in the canopy layer, which mixes surface sensible and latent heat fluxes to the wider environment, is noted as a potential driver of $T_{a}$ lapse rates and $T_{a}-$ LST linkages (Roth et al. 1989; Schwarz et al. 2012; Shiflett et al. 2017). Using wind velocity data at each land-cover plot, we found that as wind velocity approached zero so did $T_{a}$ lapse rates for several land covers. Tree-canopy sheltering effects from high daytime wind velocity are consistent with higher $T_{a}$ lapse rates. Likewise, stronger nighttime $T_{a}$-LST linkages may have been driven by decreased nighttime wind velocity, creating less microadvection and a more direct connection between surface heat flux and $T_{a}$ (Voogt and Oke 2003). It is possible that the three-dimensional structure of land-cover surfaces and associated canopylevel warming or surface-shading effects may have been a stronger driver of $T_{a}$ lapse rates and $T_{a}-\mathrm{LST}$ linkages (Kawashima et al. 2000; Schwarz et al. 2012; Shiflett et al. 2017). Both wind velocity and LST have similar daily patterns; although we did not find hysteresis, or lags, in their relationships with $T_{a}$ lapse rate, isolating their individual effects remains an important research challenge. Investigating scaling effects on $T_{a}$ lapse rate, and $T_{a}$-LST linkages, may further refine the role of wind velocity and LST drivers.

\section{b. Implications of small-scale spatial variation in $T_{a}$ and LST on their linkages}

Because of differences in surface thermal properties and shading effects, there is typically greater daytime variability in LST between surfaces than within (Unger et al. 2009; Armson et al. 2012; Gillner et al. 2015). The short- and tall-tree land covers contain a mixture of surfaces, both canopy and bare-soil interspace, and greater three-dimensional structure relative to the other land covers. Increased canopy shading effects and daytime differences in LST between canopy and interspace likely contributed to the greater spatial variation that we observed at short- and tall-tree land covers. The largest inter-land-cover temperature range was observed at 1400 PDT, near the time of highest intra-land-cover spatial variation for short and tall trees. Also, there were lower levels of daytime LST variation in the tall-tree land cover, likely due to the reduction of interspace area and increased ground-level shading. These trends in variation may have an impact on $T_{a}$-LST relationships, since land cover will contribute differently to nearsurface $T_{a}$ (Oke 1982; Roth et al. 1989). Surfaces with higher daytime LST than $T_{a}$ reemit heat during the night as sensible heat flux (Landsberg 1981; Roth et al. 1989). Furthermore, irrigated environments in arid and semiarid cities may have greater sensible heat fluxes relative to similar land covers in a temperate climate (Oke 1982, 
1987; Grimmond and Oke 1995). Consistent with other urban warming studies, we found effects of small-scale surface thermal properties on LST and cumulative three-dimensional thermal-property and wind velocity effects on $T_{a}$ (Voogt and Oke 2003; Lo and Quattrochi 2003; Stathopoulou and Cartalis 2007). In conjunction with resolving land-cover effects on $T_{a}$ and LST relationships, an important next step to our findings is a determination of the effects of spatial resolution on this linkage.

When quantifying land-cover temperature effects, we further found important distinctions between LST and vertical gradients in $T_{a}$. As this study shows, LST does not have a consistent relationship with $T_{a}$ across landcover types. Land-use and land-cover patches have irregular boundaries, contributing to mixed pixel error and poor $T_{a}$-LST linkage when using relatively coarse and spatially uniform units (Stone and Norman 2006; Schwarz et al. 2012). Furthermore, we found that vertical height and wind velocity affected $T_{a}$-LST linkages. Slopes between $T_{a}$ and LST among land covers at $1.5 \mathrm{~m}$ ranged from 0.49 to 0.89 , consistent with prior estimates of urban $T_{a}$ at $70 \%$ of LST warming (Klok et al. 2012). These findings suggest that remote sensing studies that quantify urban warming effects through surface temperatures may overestimate (e.g., asphalt, bare-surface, and tree land covers) or underestimate (e.g., grass land cover) the extent of $T_{a}$ warming. Current modeling approaches that use LST to estimate $T_{a}$, such as TopoWx (http://www.ntsg.umt.edu/project/TopoWx), currently do not factor in temporally specific land-cover relationships (Oyler et al. 2016). A land-cover-specific approach of estimating urban $T_{a}$ spatial variation using remotely sensed LST will likely be more useful, especially for pixels with mixed land uses as are typically acquired from satellite platforms.

\section{c. Vegetation feedbacks to humidity and vapor pressure deficit}

Our results of higher canopy-level RH at short- and tall-tree land covers than at asphalt land covers $(6.2 \%$ and $6.1 \%$, respectively) were consistent with other studies that saw $0.5 \%-6.4 \%$ (Gillner et al. 2015) and $9.0 \%-20.0 \%$ (Souch and Souch 1993) increases in RH beneath trees. We also observed higher RH in turf grass than in other land covers $(6.4 \%$ and $4.7 \%$ increase over asphalt and bare surface, respectively). This finding, along with observed decreases in $T_{a}$ at the grass land cover, is important since standardized weather measurements are typically made at $1.5 \mathrm{~m}$ over turf grass (WMO 2008); thus, studies that analyze urban microclimate using standardized meteorological stations may not capture the upper range of $T_{a}$ and lower range of $\mathrm{RH}$ in semiarid environments. Although we observed higher RH at short- and tall-tree land covers, there was not an increase in crown-level $(1.5 \mathrm{~m}) \mathrm{RH}$ associated with transpiration relative to near-surface $(0.1 \mathrm{~m}) \mathrm{RH}$. This is consistent with other studies that have found no effects, or a decrease, in crown-level RH in urban trees, particularly at night when canopies provide shelter from dew (Gillner et al. 2015). Instead, we found that increasing wind velocity minimizes RH lapse rates, indicating that wind may have larger effects on the upper canopy boundary layer. Despite no canopy-level increases in $\mathrm{RH}$, consistent with evapotranspiration feedbacks to reduced plant stress responses (Chen et al. 2012; Litvak et al. 2013) and increased irrigation effects on microclimate, we found both higher $\mathrm{RH}$ and lower VPD over vegetated land covers. This effect was most clear in the grass land cover where there were positive and increasing daytime VPD lapse rates despite a decreasing trend in $T_{a}$ lapse rates.

\section{d. Synthesis}

We empirically evaluated vertical microscale atmospheric profiles and explicitly connected these to remotely sensed surface temperatures and showed how land surface characteristics, from relatively simple bare surfaces to complex shading from trees, differ in their microclimate distributions. These findings empirically highlight that vertical variation can be as large as the differences between land covers as predicted from modeling studies (Taleghani et al. 2016). The large variation among land-cover types in their vertical microclimate distributions is coupled to surface characteristics and is also influenced by larger-scale meteorological variation. Our findings help to develop better assessments of urban heat risk and vulnerability that consider both surface and air characteristics. With the rapidly expanding use of surface temperature measurements to assess heat vulnerability (Harlan et al. 2013; Jenerette et al. 2016), our results show how this remotely sensed heat metric is connected to air temperature through land-cover-specific vertical functions. The vertical temperature profiles within the first $2 \mathrm{~m}$ from the surface can have a strong influence on heat vulnerability, especially for children whose body core is closer to the ground (Vanos 2015; Vanos et al. 2016). Policy assessments of heat mitigation strategies that evaluate altered urban land-cover patterns to reduce heat vulnerability currently do not address vertical temperature variation (Georgescu et al. 2014; Vahmani and Ban-Weiss 2016). Research directed to evaluating microclimate lapse rates and $T_{a}$-LST relationships in mixed urban land covers are important future directions to minimize potential urban heat vulnerability. 
Acknowledgments. This study was supported by NASA through Grant NNX12AQ02G and the National Science Foundation through CBET-1444758. We thank Sofia G. Koutzoukis, Bruno Pita, Holly M. Andrews, and Peter C. Ibsen for field help and consultation.

\section{REFERENCES}

Armson, D., P. Stringer, and A. R. Ennos, 2012: The effect of tree shade and grass on surface and globe temperatures in an urban area. Urban For. Urban Greening, 11, 245-255, doi:10.1016/j.ufug.2012.05.002.

_- M. A. Rahman, and A. R. Ennos, 2013: A comparison of the shading effectiveness of five different street tree species in Manchester, UK. Arboric. Urban For., 39, 157-164. [Available online at http://joa.isa-arbor.com/request.asp? JournalID $=1 \&$ ArticleID $=3278 \&$ Type $=2$.]

Aubrecht, D. M., B. R. Helliker, M. L. Goulden, D. A. Roberts, C. J. Still, and A. D. Richardson, 2016: Continuous, long-term, high-frequency thermal imaging of vegetation: Uncertainties and recommended best practices. Agric. For. Meteor., 228-229, 315-326, doi:10.1016/j.agrformet.2016.07.017.

Barreca, A. I., and J. P. Schimshack, 2012: Absolute humidity, temperature, and influenza mortality: 30 years of country-level evidence from the United States. Amer. J. Epidemiol., 176 (Suppl.), 114-122, doi:10.1093/aje/kws259.

Buyantuyev, A., and J. G. Wu, 2010: Urban heat island and landscape heterogeneity: Linking spatiotemporal variations in surface temperature to land-cover and socioeconomic patterns. Landscape Ecol., 25, 17-33, doi:10.1007/s10980-009-9402-4.

Chakraborty, S. D., Y. Kant, and D. Mitra, 2015: Assessment of land surface temperature and heat fluxes over Delhi using remote sensing data. J. Environ. Manage., 148, 143-152, doi:10.1016/j.jenvman.2013.11.034.

Chen, C., 2015: Determining the leaf emissivity of three crops by infrared thermometry. Sensors, 15, 11387-11401, doi:10.3390/ s150511387.

Chen, L., Z. Zhang, and B. E. Ewers, 2012: Urban tree species show the same hydraulic response to vapor pressure deficit across varying tree size and environmental conditions. PLoS One, 7, e47882, doi:10.1371/journal.pone.0047882.

Coseo, P., and L. Larsen, 2014: How factors of land use/land cover, building configuration, and adjacent heat sources and sinks explain urban heat islands in Chicago. Landscape Urban Plann., 125, 117-129, doi:10.1016/j.landurbplan.2014.02.019.

Crum, S. M., L. L. Liang, and G. D. Jenerette, 2016: Landscape position influences soil respirations variability and sensitivity to physiological drivers in mixer-use lands of Southern California, USA. J. Geophys. Res. Biogeosci., 121, 2530-2543, doi:10.1002/2016JG003469.

_ _ S. A. Schiflett, and G. D. Jenerette, 2017: The influence of vegetation, mesoclimate and meteorology on urban atmospheric microclimates across a coastal to desert climate gradient. J. Environ. Manage., 200, 295-303, doi:10.1016/j.jenvman.2017.05.077.

Davis, A. Y., J. Jung, B. C. Pijanowski, and E. S. Minor, 2016: Combined vegetation volume and "greenness" affect urban air temperature. Appl. Geogr., 71, 106-114, doi:10.1016/ j.apgeog.2016.04.010.

Doran, J. C., J. M. Hubbe, J. C. Liljegren, W. J. Shaw, G. J. Collatz, D. R. Cook, and R. L. Hart, 1998: A technique for determining the spatial and temporal distributions of surface heat fluxes of heat and moisture over the Southern Great Plains Cloud and Radiation Testbed. J. Geophys. Res., 103, 6109-6121, doi:10.1029/97JD03427.

Feyisa, G. L., K. Dons, and H. Meilby, 2014: Efficiency of parks in mitigating urban heat island effect: An example from Addis Ababa. Landscape Urban Plann., 123, 87-95, doi:10.1016/j.landurbplan.2013.12.008.

Gallo, K. P., A. L. McNab, T. R. Karl, J. F. Brown, J. J. Hood, and J. D. Tarpley, 1993: The use of a vegetation index for assessment of the urban heat island effect. Int. J. Remote Sens., 14, 2223-2230, doi:10.1080/01431169308954031.

Gao, C. X., Y. G. Qian, N. Wang, L. L. Ma, and X. G. Jiang, 2015: Land surface emissivity retrieval from airborne hyperspectral scanner thermal infrared data over urban surfaces. International Conference on Intelligent Earth Observing and Applications 2015, G. Zhou and C. Kang, Eds., International Society for Optics and Photonics (SPIE Proceedings, Vol. 9808), 980823, doi:10.1117/12.2220606.

Gao, J., Y. Sun, Y. Lu, and L. Li, 2014: Impact of ambient humidity on child health: A systematic review. PLoS One, 9, e112508, doi:10.1371/journal.pone.0112508.

Georgescu, M., P. E. Morefield, B. G. Bierwagen, and C. P. Weaver, 2014: Urban adaptation can roll back warming of emerging megapolitan regions. Proc. Natl. Acad. Sci. USA, 111, 2909-2914, doi:10.1073/pnas.1322280111.

Gillner, S., J. Vogt, S. Dettman, and A. Roloff, 2015: Role of street trees in mitigating effects of heat and drought at highly sealed urban sites. Landscape Urban Plann., 143, 33-42, doi:10.1016/ j.landurbplan.2015.06.005.

Grimmond, S., and T. R. Oke, 1995: Comparison of heat fluxes from summertime observations in the suburbs of four North American cities. J. Appl. Meteor., 34, 873-889, doi:10.1175/ 1520-0450(1995)034<0873:COHFFS $>2.0 . \mathrm{CO} ; 2$.

Hall, S. J., and Coauthors, 2016: Convergence of microclimate in residential landscapes across diverse cities in the United States. Landscape Ecol., 31, 101-117, doi:10.1007/ s10980-015-0297-y.

Harlan, S. L., A. J. Brazel, L. Prashad, W. L. Stefanov, and L. Larsen, 2006: Neighborhood microclimates and vulnerability to heat stress. Soc. Sci. Med., 63, 2847-2863, doi:10.1016/ j.socscimed.2006.07.030.

— J. H. Declet-Barreto, W. L. Stefanov, and D. B. Petitti, 2013: Neighborhood effects on heat deaths: Social and environmental predictors of vulnerability in Maricopa County, Arizona. Environ. Health Perspect., 121, 197-204, doi:10.1289/ ehp.1104625.

Hartz, D. A., L. Prashad, B. C. Hedquist, J. Golden, and A. J. Brazel, 2006: Linking satellite images and hand-held infrared thermography to observed neighborhood climate conditions. Remote Sens. Environ., 104, 190-200, doi:10.1016/j.rse.2005.12.019.

Imhoff, M. L., P. Zhang, R. E. Wolfe, and L. Bounoua, 2010: Remote sensing of the urban heat island effect across biomes in the continental USA. Remote Sens. Environ., 114, 504-513, doi:10.1016/j.rse.2009.10.008.

Jenerette, G. D., S. L. Harlan, W. L. Stefanov, and C. A. Martin, 2011: Ecosystem services and urban heat riskscape moderation: Water, green spaces, and social inequality in Phoenix, USA. Ecol. Appl., 21, 2637-2651, doi:10.1890/10-1493.1.

, and Coauthors, 2016: Micro-scale urban surface temperatures are related to land-cover features and residential heat related health impacts in Phoenix, AZ USA. Landscape Ecol., 31, 745-760, doi:10.1007/s10980-015-0284-3. 
Kawashima, S., T. Ishida, M. Minomura, and T. Miwa, 2000: Relations between surface temperature and air temperature on a local scale during winter nights. J. Appl. Meteor., 39, 1570-1579, doi:10.1175/1520-0450(2000)039<1570:RBSTAA $>2.0$.CO;2.

Klok, L., S. Zwart, H. Verhagen, and E. Mauri, 2012: The surface heat island of Rotterdam and its relationship with urban surface characteristics. Resour. Conserv. Recycl., 64, 23-29, doi:10.1016/j.resconrec.2012.01.009.

Landsberg, H. E., 1981: The Urban Climate. Academic Press, $275 \mathrm{pp}$

Lee, H., J. Holst, and H. Mayer, 2013: Modification of humanbiometeorologically significant radiant flux densities by shading as local method to mitigate heat stress in summer within urban street canyons. Adv. Meteor., 2013, 312572, doi:10.1155/2013/312572.

Lin, B. S., and Y. J. Lin, 2010: Cooling effect of shade trees with different characteristics in a subtropical urban park. HortScience, 45, 83-86.

Litvak, E., N. Bijoor, and D. E. Pataki, 2013: Adding trees to irrigated turfgrass lawns may be a water-saving measure in semiarid environments. Ecohydrology, 7, 1314-1330, doi:10.1002/ eco.1458.

Lo, C. P., and D. A. Quattrochi, 2003: Land-use and land-cover change, urban heat island phenomenon, and health implications: A remote sensing approach. Photogramm. Eng. Remote Sens., 69, 1053-1063, doi:10.14358/PERS.69.9.1053.

Myint, S. W., E. A. Wentz, A. J. Brazel, and D. A. Quattrochi, 2013: The impact of distinct anthropogenic and vegetation features on urban warming. Landscape Ecol., 28, 959-978, doi:10.1007/ s10980-013-9868-y.

Oke, T. R., 1982: The energetic basis of the urban heat island. Quart. J. Roy. Meteor. Soc., 108, 1-24, doi:10.1002/ qj.49710845502.

— 1987: Boundary Layer Climate. 2nd ed. Routledge, 435 pp.

Oswald, E. M., R. B. Rood, K. Zhang, C. J. Gronlund, M. S. O'Neill, J. L. White-Newsome, S. J. Brines, and D. G. Brown, 2012: An investigation into the spatial variability of near-surface air temperatures in the Detroit, Michigan, metropolitan region. J. Appl. Meteor. Climatol., 51, 1290-1304, doi:10.1175/JAMC-D-11-0127.1.

Oyler, J. W., S. Z. Dobrowski, Z. A. Holden, and S. W. Running, 2016: Remotely sensed land skin temperature as a spatial predictor of air temperature across conterminous United States. J. Appl. Meteor. Climatol., 55, 1441-1457, doi:10.1175/ JAMC-D-15-0276.1.

Parris, K. M., and D. L. Hazell, 2005: Biotic effects of climate change in urban environments: The case of the grey-headed flying fox (Pteropus poliocephalus) in Melbourne, Australia. Biol. Conserv., 124, 267-276, doi:10.1016/j.biocon.2005.01.035.

Potchter, O., P. Cohen, and A. Bitan, 2006: Climatic behavior of various urban parks during hot and humid summer in the Mediterranean city of Tel Aviv, Israel. Int. J. Climatol., 26, 1695-1711, doi:10.1002/joc.1330.

Roth, M., T. R. Oke, and W. J. Emery, 1989: Satellite-derived urban heat islands from three coastal cities and the utilization of such data in urban climatology. Int. J. Remote Sens., 10, 16991720, doi:10.1080/01431168908904002.

Santamouris, M., 2015: Analyzing the heat island magnitude and characteristics in one hundred Asian and Australian cities and regions. Sci. Total Environ., 512-513, 582-598, doi:10.1016/j.scitotenv.2015.01.060.

Schwarz, N., U. Schlink, U. Franck, and K. Großmann, 2012: Relationship of land surface and air temperatures and its impli- cations for quantifying urban heat island indicators-An application for the city of Leipzig (Germany). Ecol. Indic., 18, 693-704, doi:10.1016/j.ecolind.2012.01.001.

Shashua-Bar, I., and M. E. Hoffman, 2000: Vegetation as a climatic component in the design of an urban street: An empirical model for predicting the cooling effect of urban green areas with trees. Energy Build., 31, 221-235, doi:10.1016/S0378-7788(99)00018-3.

Shiflett, S. A., L. L. Liang, S. M. Crum, G. L. Feyisa, J. Wang, and G. D. Jenerette, 2017: Variation in the urban vegetation, surface temperature, air temperature nexus. Sci. Total Environ., 579, 495-505, doi:10.1016/j.scitotenv.2016.11.069.

Souch, C. A., and C. Souch, 1993: The effect of trees on summertime below canopy urban climates: A case study Bloomington, Indiana. J. Arboric., 19, 303-312.

Stabler, L. B., C. A. Martin, and A. J. Brazel, 2005: Microclimates in a desert city were related to land use and vegetation index. Urban For. Urban Green., 3, 137-147, doi:10.1016/j.ufug.2004.11.001.

Stathopoulou, M., and C. Cartalis, 2007: Daytime urban heat islands from Landsat ETM+ and Corine land cover data: An application to major cities in Greece. Sol. Energy, 81, 358-368, doi:10.1016/j.solener.2006.06.014.

Steadman, R. G., 1979: The assessment of sultriness. Part I: A temperature-humidity index based on human physiology and clothing science. J. Appl. Meteor., 18, 861-873, doi:10.1175/ 1520-0450(1979)018<0861:TAOSPI > 2.0.CO;2.

Stone, B., and J. M. Norman, 2006: Land use planning and surface heat island formation: A parcel-based radiation flux approach. Atmos. Environ., 40, 3561-3573, doi:10.1016/j.atmosenv.2006.01.015.

Streiling, S., and A. Matzarakis, 2003: Influence of single and small clusters of trees on the bioclimate of a city: A case study. J. Arboric., 29, 309-316.

Taha, H., 1997: Urban climates and heat islands: Albedo, evapotranspiration, and anthropogenic heat. Energy Build., 25, 99-103, doi:10.1016/S0378-7788(96)00999-1.

Taleghani, M., D. Sailor, and G. A. Ban-Weiss, 2016: Micrometeorological simulations to predict the impacts of heat mitigation strategies on pedestrian thermal comfort in a Los Angeles neighborhood. Environ. Res. Lett., 11, 024003, doi:10.1088/ 1748-9326/11/2/024003.

Tayyebi, A., and G. D. Jenerette, 2016: Increases in the climate change adaptation effectiveness and availability of vegetation across a coastal to desert climate gradient in metropolitan Los Angeles, CA, USA. Sci. Total Environ., 548-549, 60-71, doi:10.1016/j.scitotenv.2016.01.049.

Tonolla, D., V. Acuña, U. Uehlinger, T. Frank, and K. Tockner, 2010: Thermal heterogeneity in river floodplains. Ecosystems, 13, 727-740, doi:10.1007/s10021-010-9350-5.

Unger, J., T. Gal, J. Rakonczai, L. Mucsi, J. Szatmári, Z. Tobak, B. van Leeuwen, and K. Fiala, 2009: Air temperature versus surface temperature in urban environment. Seventh Int. Conf. on Urban Climate, Yokohama, Japan, International Association for Urban Climate, A17-6. [Available online at http:// www.ide.titech.ac.jp/ icuc7/extended_abstracts/pdf/375624-1090514014110-003.pdf.]

Vahmani, P., and G. A. Ban-Weiss, 2016: Climatic consequences of adopting drought-tolerant vegetation over Los Angeles as a response to California drought. Geophys. Res. Lett., 43, 8240-8249, doi:10.1002/2016GL069658.

Vanos, J. K., 2015: Children's health and vulnerability in outdoor microclimates: A comprehensive review. Environ. Int., 76, 1-15, doi:10.1016/j.envint.2014.11.016. 
, A. Middle, G. R. Mckercher, E. R. Kuras, and B. L. Ruddell, 2016: Hot playgrounds and children's health: A multiscale analysis of surface temperatures in Arizona, USA. Landscape Urban Plann., 146, 29-42, doi:10.1016/j.landurbplan.2015.10.007.

Voogt, J. A., and T. R. Oke, 2003: Thermal remote sensing of urban climates. Remote Sens. Environ., 86, 370-384, doi:10.1016/ S0034-4257(03)00079-8.

WMO, 2008. Guide to meteorological instruments and methods of observation. 7th ed. WMO Rep. 8, 681 pp.
[Available online at http://www.wmo.int/pages/prog/www/ IMOP/CIMO-Guide.html.]

Yang, F., S. S. Y. Lau, and F. Qian, 2011: Urban design to lower summertime outdoor temperatures: An empirical study on high-rise housing in Shanghai. Build. Environ., 46, 769-785, doi:10.1016/j.buildenv.2010.10.010.

Zhao, L., X. Lee, R. B. Smith, and K. Oleson, 2014: Strong contributions of local background climate to urban heat islands. Nature, 511, 216-219, doi:10.1038/nature13462. 